\title{
Effects of an external resistance on maximum flow in chronic obstructive lung disease: implications for recognition of coincident upper airway obstruction
}

\author{
D R ROBERTSON,C R SWINBURN, T N STONE, G J GIBSON \\ From the Department of Respiratory Medicine, Freeman Hospital, Newcastle upon Tyne
}

\begin{abstract}
To determine how the presence of generalised airflow limitation due to chronic obstructive lung disease affects the recognition of simulated upper airway obstruction, a study was carried out in 12 patients (mean (SD) age 57 (7) years) with chronic obstructive lung disease (FEV $\%$ predicted 53 (22), range 21-70) and 12 matched control subjects. Patients and control subjects performed maximal inspiratory and expiratory flow-volume curves in a variable volume plethysmograph with and without upper airway obstruction simulated at the mouth with a series of polythene washers of internal diameter 4,6,8,10, and $12 \mathrm{~mm}$. In patients, as in normal subjects, peak expiratory flow (PEF) and maximum inspiratory flow at $50 \%$ of vital capacity (Vimax ( $_{50}$ ) were more sensitive to upper airway obstruction than were $\mathrm{FEV}_{1}$ or maximum expiratory flow at $50 \% \mathrm{VC}$ $\left(\dot{V}_{E m a x}\right)$; but the reductions in all indices caused by simulated upper airway obstruction were smaller in the patients than in the controls. The fall in PEF (whether expressed in absolute units or as a percentages) consequent on severe $(4 \mathrm{~mm})$ upper airway obstruction became smaller with increasing severity of chronic obstructive lung disease. The subjects also produced flow-volume curves with and without $6 \mathrm{~mm}$ upper airway obstruction while breathing helium and oxygen (heliox). In both groups the effects of heliox on PEF and VImax ${ }_{50}$ were increased when upper airway obstruction was simulated. It was confirmed that the functional recognition of upper airway obstruction is more difficult in patients with chronic obstructive lung disease than in normal subjects and this difficulty increases with severity of disease; an unusually large increase in PEF or Vimax so $_{50}$ while the patient is breathing heliox should raise the suspicion of coexisting upper airway obstruction, but such a pattern is not specific.
\end{abstract}

\section{Introduction}

Upper airway obstruction is recognised functionally by its effects on maximum expiratory and inspiratory flow. Extrathoracic obstruction has its greatest effect on the maximum flows that are most effort dependent-for example, maximum expiratory flow at large lung volumes and maximum inspiratory flow throughout the vital capacity. Various indices based on flowvolume and spirometric measurements have been proposed to aid the recognition and assessment of upper airway obstruction-for example, a peak expiratory flow (PEF) that is unexpectedly low in

Address for reprint requests: Dr G J Gibson, Department of Respiratory Medicine, Freeman Hospital, Newcastle upon Tyne NE7 7DN.

Accepted 10 March 1989 relation to the forced expiratory volume in one second $\left(\mathrm{FEV}_{1}\right)^{1}$ or an abnormally high ratio of maximum mid expiratory to maximum mid inspiratory flow. ${ }^{23}$

Lesions in the larynx or trachea may sometimes lead to upper airway obstruction in patients who also have generalised airflow limitation, and clinical experience suggests that in such patients upper airway obstruction may be more difficult to recognise. Theoretical considerations imply that this would be the case, because maximum expiratory flows are less dependent on effort in patients with chronic airflow limitation than in normal subjects. Indeed, a degree of upper airway obstruction may even be beneficial in such patients: the characteristic "pursed lips" breathing seen in advanced emphysema represents self imposed upper airway obstruction.

Airflow in the central airways is turbulent and very dependent on the density of the gas breathed. ${ }^{4}$ Breathing a low density gas, such as a $79 \%$ helium and $21 \%$ 
oxygen mixture (heliox), should result in increased flow, particularly when this is determined by the calibre of the more central airways. Comparison of maximum flows during the breathing of air and of heliox has been used in an attempt to identify the site of airflow obstruction (for example, in asthma ${ }^{5}$ ) and it has been suggested that the response to heliox may aid recognition of upper airway obstruction in patients with chronic obstructive lung disease. ${ }^{6}$ We have compared the effects of artificially induced upper airway obstruction on maximum airflow in patients with chronic obstructive lung disease and normal subjects to examine how chronic obstructive lung disease affects the functional recognition of upper airway obstruction and how the responses of maximum expiratory and inspiratory flow to heliox might aid recognition of upper airway obstruction in such patients.

\section{Methods}

\section{SUBJECTS}

We studied 12 patients (11 male) with stable chronic obstructive lung disease and 12 normal subjects of similar age and sex distribution. Patients were recruited if the ratio of $\mathrm{FEV}_{1}$ to vital capacity was less than $60 \%$, and they were selected to represent a wide range of severity of generalised airways obstruction. Details of the personal characteristics and results of baseline pulmonary function tests for the two groups are shown in table 1.

\section{DESIGN OF STUDY}

Maximum expiratory (MEFV) and inspiratory (MIFV) flow-volume curves were obtained with the subject seated in a variable volume plethysmograph.? A nose clip was worn. Flow was measured at the mouth by electrical differentiation of expired volume by means of a rolling seal spirometer with a flat frequency response to $15 \mathrm{~Hz}$ (Ohio 842); the volume recorded was change in thoracic gas volume. $\mathrm{FEV}_{1}$ was measured by the rolling seal spirometer. The flowvolume curves were plotted directly on a rapidly responding X-Y recorder (Hewlett Packard 7054A). An $\mathrm{X}-\mathrm{Y}$ recorder was chosen in preference to a cathode ray oscilloscope to aid resolution of low values of flow. To check that the response rate of the recorder was sufficiently rapid for faithful recording of high flows, a preliminary study was performed in one healthy subject, in whom MEFV curves were recorded simultaneously on the $\mathrm{X}-\mathrm{Y}$ recorder and a cathode ray oscilloscope; this showed no significant difference in the values of PEF recorded by the two methods (mean (SD) difference of 20 consecutive readings 0.06 $\left.(0 \cdot 17) 1 \mathrm{~s}^{-1}\right)$.

All the subjects initially practised the breathing
Table 1 Personal characteristics and baseline pulmonary function (mean (SD) and range)

\begin{tabular}{|c|c|c|}
\hline & Patients $(n=12)$ & Controls $(n=12)$ \\
\hline 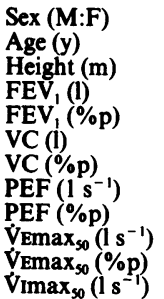 & $\begin{array}{l}11: 1 \\
56.8(6.7)(48-66) \\
1.74(0.07)(1.59-1.88) \\
1.71(0.77)(0.7-3 \cdot 1) \\
53(22)(21-90) \\
3.81(0.99)(2 \cdot 7-5.0) \\
91(19)(60-118) \\
4.70(1.84)(1.9-8.1) \\
57(22)(25-95) \\
1.85(1.13)(0.45-3.75) \\
42(24)(9-83) \\
4.5(1.8)(1.2-7.7)\end{array}$ & $\begin{array}{c}11: 1 \\
58 \cdot 2(9 \cdot 7)(45-74) \\
1 \cdot 72(0.05)(1.63-1 \cdot 78) \\
3 \cdot 22(0 \cdot 30)(2 \cdot 8-3 \cdot 8) \\
103(11 \cdot 5)(91-131) \\
4.90(0 \cdot 77)(3 \cdot 6-5 \cdot 9) \\
119(17)(99-155) \\
8.47(1.34)(6.5-11 \cdot 3) \\
106(17)(80-134) \\
4.47(0.85)(3.3-6 \cdot 0) \\
103(19)(77-134) \\
6.0(1.3)(4.4-8.1)\end{array}$ \\
\hline
\end{tabular}

FEV -forced expiratory volume in one second; \%p-percentage of predicted value ${ }^{10}$; VC - vital capacity; PEF-peak expiratory flow; $\mathrm{VEmax}_{50,} \mathrm{VImax}_{50}$-maximum expiratory and inspiratory flow at $50 \%$ of $\mathrm{VC}$.

manoeuvres necessary for obtaining reproducible maximum flow-volume curves. Each then performed a series of maximum expiratory and inspiratory efforts, breathing air with and without simulated upper airway obstruction of varying severity. Upper airway obstruction was imposed by the method of Miller and Hyatt, ${ }^{8}$ by inserting (one at a time and in random order) polythene washers with internal diameters of $4,6,8$, 10 , and $12 \mathrm{~mm}$ between the mouthpiece and the spirometer. Each subject then breathed tidally from a bag containing heliox until the concentration of nitrogen in mixed expired air measured by a mass spectrometer was under $5 \%$. With the subject still breathing heliox flow-volume curves were again recorded, first with no additional obstruction and then through a $6 \mathrm{~mm}$ orifice. Only one orifice was used for the heliox recordings.

For each recording at least three expiratory and inspiratory curves were obtained from each subject and these were used to construct a composite maximum flow-volume loop by the envelope method, ${ }^{9}$ with the largest vital capacity as a reference and the other two curves superimposed. Efforts were regarded as satisfactory only if vital capacity was within $5 \%$ of the largest value. PEF, peak inspiratory flow (PIF), and maximum expiratory and inspiratory flows at $50 \%$ of vital capacity $\left(\dot{V}_{E m a x}\right.$, VImax $_{50}$ ) were read directly for the composite curves. Values of FEV, PEF and $\dot{V}_{E m a x}{ }_{50}$ were compared with reference values ${ }^{10}$; because of the paucity of appropriate reference values Vimax $_{50}$ is reported only in absolute units.

\section{ANALYSIS OF RESULTS}

The $\mathrm{FEV}_{1}$ (\% predicted) measured conventionally and with no added obstruction was taken as the index of severity of chronic obstructive lung disease. The effects of simulated upper airway obstruction in the two groups of subjects breathing air were analysed initially 

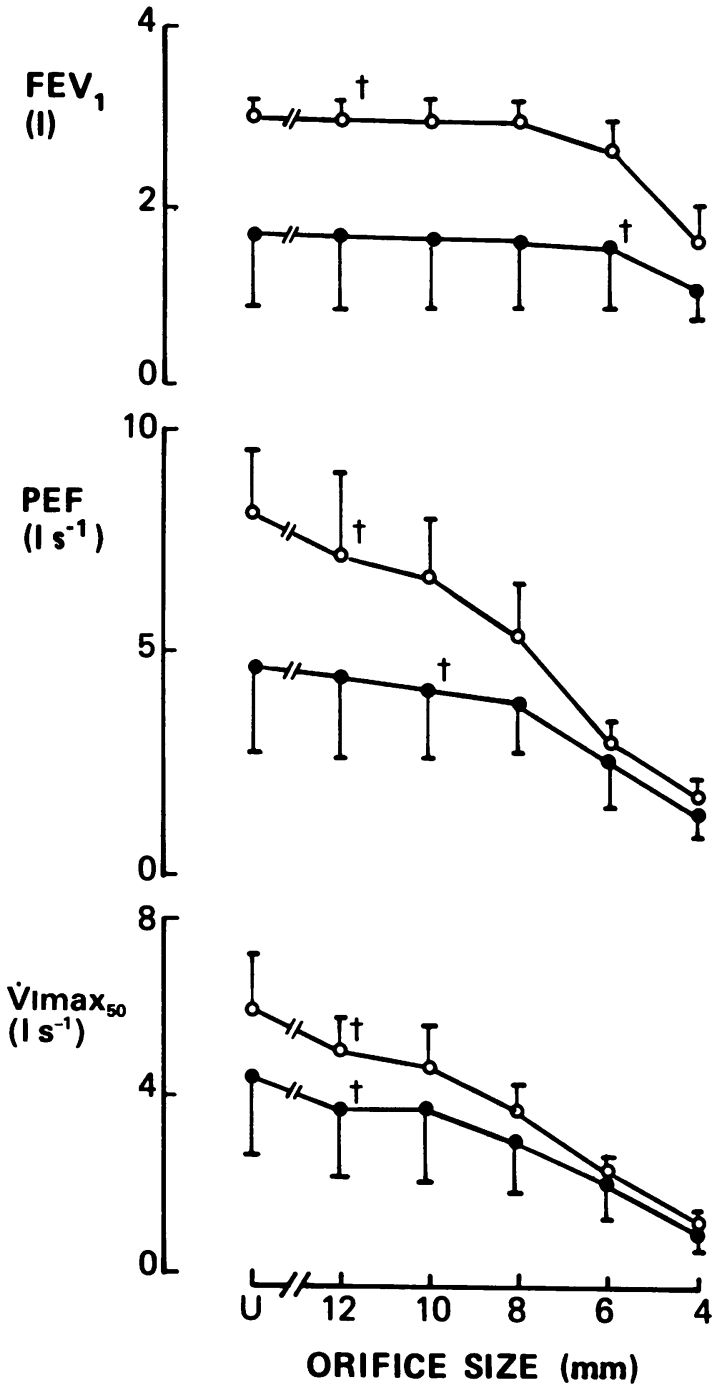

Fig 1 Effect of simulated upper airway obstruction (UAO) of increasing severity on the forced expiratory volume in one second $\left(F E V_{1}\right)$, peak expiratory flow $(P E F)$, and maximum mid inspiratory flow ( $\dot{V}_{\text {Imax }}$ ) expressed in absolute units (mean and SD). patients; $\bigcirc$ controls. $\dagger$ denotes least level of simulated upper airway obstruction at which the reductions in FEV , PEF, or VImax ${ }_{50}$ from the "unobstructed" level became significant. $U$ indicates values "unobstructed."

in terms of the differences in each index obtained with and without each orifice expressed in absolute units (litres for $\mathrm{FEV}_{1}$, and $1 \mathrm{~s}^{-1}$ for PEF, VEmax $\dot{V}^{\prime} \max _{50}$ ). Percentage changes in each index were examined subsequently. The effect of breathing heliox was assessed in terms of the percentage changes in
$\mathrm{FEV}_{1}$ and flow indices $(\triangle \mathrm{FEV}, \%, \triangle \mathrm{PEF} \%$, etc) from the values obtained during air breathing. These percentage changes were calculated with no added obstruction and in the presence of the $6 \mathrm{~mm}$ orifice for both groups of subjects.

Statistical analyses within and between groups of subjects were performed with Student's $t$ tests for paired and unpaired data respectively. Linear correlations between variables were examined using the method of least squares. A p value of $<0.05$ was considered significant.

\section{Results}

EFFECT OF UPPER AIR WAY OBSTRUCTION OF INCREASING SEVERITY ON FEV 1 AND INDICES OF AIRFLOW

The effects of the various orifices on the absolute values of $F E V_{1}, P E F$, and $\dot{V}_{1 m a x}$ in patients and control subjects breathing room air are shown in figure 1 and the reductions in each index (in absolute and proportional terms) with each orifice from the values with unobstructed breathing in figures 2-4. Both $\dot{V} \max _{50}$ and PEF were significantly reduced with mild simulated upper airway obstruction (12 $\mathrm{mm}$ orifice for each index in control subjects, $12 \mathrm{~mm}$ for Vं $\max _{50}$ and $10 \mathrm{~mm}$ for PEF in patients). These indices were more sensitive to the presence of upper airway obstruction than the $F_{1}$ or $\dot{V E m a x}_{50}$ (not illustrated) in both patients and controls. The percentage reductions in PEF and Vimax ${ }_{50}$ with all degrees of upper airway obstruction in both patients and controls were also greater than the corresponding proportional reductions in $F E V_{1}$ and $\dot{V}_{\text {Emax }}$. This relative insensitivity of the $F_{E V}$ to the presence of upper airway obstruction is well illustrated in fig 1 . Overall, VEmax ${ }_{50}$ was the least sensitive index of upper airway obstruction, with no significant fall seen until the level of upper airway obstruction was severe (controls $6 \mathrm{~mm}$, patients $4 \mathrm{~mm}$ ). The reductions in $F E V_{1}, P E F$, and to a lesser degree $\dot{V}_{\text {Imax }}$ so seen with simulated upper airway obstruction in the control group were in general larger than in the patient group (fig $2 a$ ). When the reductions were expressed in percentage terms, the lower starting value in the patients thus being taken into account, the difference between subject groups was less evident but was still present (fig $2 b$ ).

RELATION BETWEEN SEVERITY OF CHRONIC OBSTRUCTIVE LUNG DISEASE AND THE EFFECT OF SEVERE UPPER AIR WAY OBSTRUCTION

The effect of severity of chronic obstructive lung disease on the identification of additional upper airway obstruction was examined by plotting, for the patient group only, the fall in PEF produced by adding a $4 \mathrm{~mm}$ orifice against $\mathrm{FEV}_{1}$ (\% predicted) (fig $3 a, b$ ). 
Fall in

FEV,

(I)

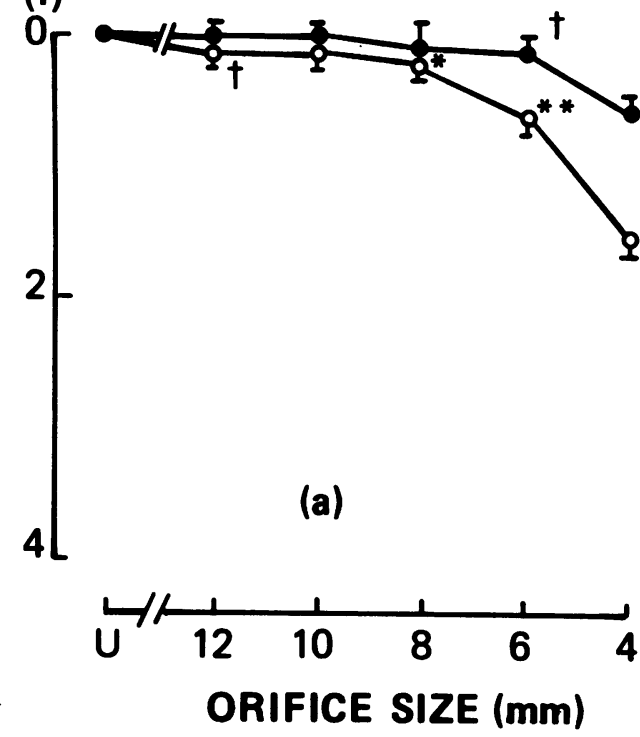

Fall in

PEF

$\left(1 \mathrm{~s}^{-1}\right)$

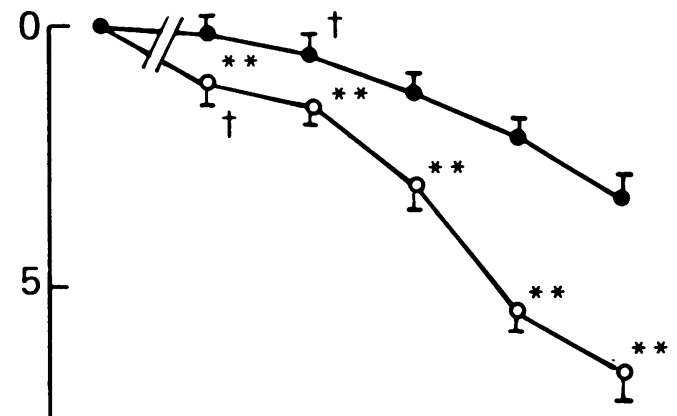

(a)

10L

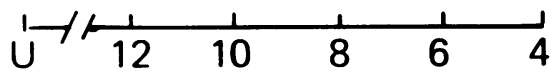

Fall in

FEV,

(\%)

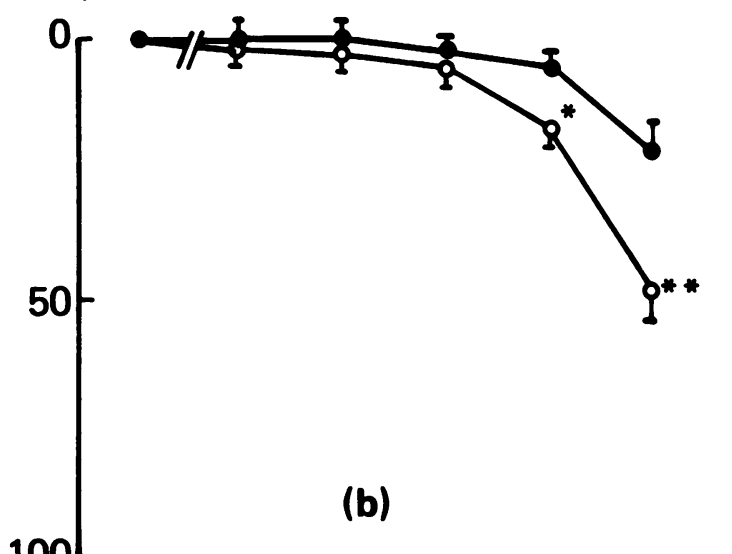

$100 \mathrm{~L}$

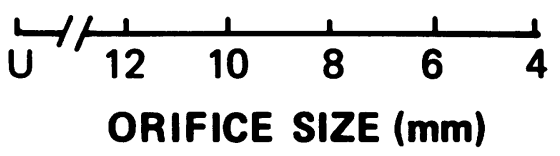

Fall in

PEF

(\%)

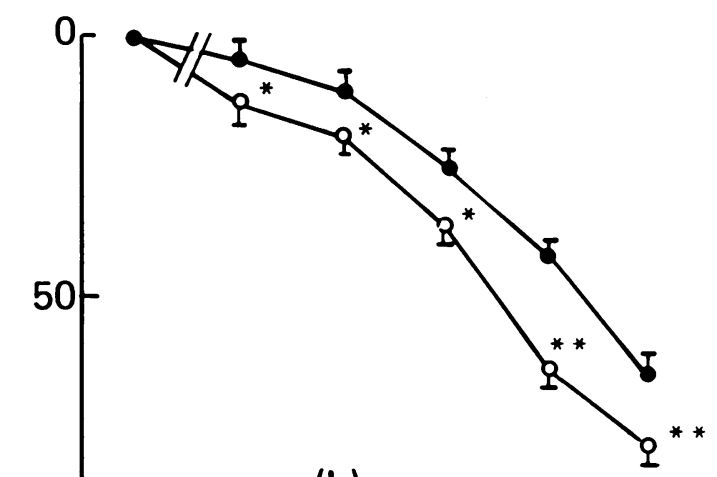

(b)

$100 \mathrm{~L}$

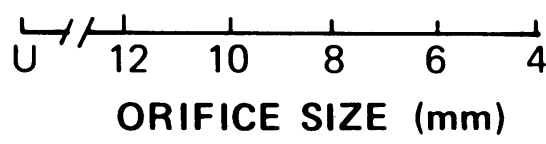

B ORIFICE SIZE (mm)

Fig 2 Mean (SEM) reduction in lung function expressed ( $a$ ) in absolute units and (b) as percentages of the "unobstructed" values seen with simulated upper airways obstruction of increasing severity. A-forced expiratory volume in one second; $B$-peak expiratory flow; $C$ (facing page)—maximum mid inspiratory flow ( $\dot{V}_{\text {Imax }}$ so). patients; $\bigcirc$ controls. $\dagger$ denotes the least level of simulated upper airway obstruction at which the absolute reduction compared with the unobstructed state became significant. Significance of differences between patients and controls: ${ }^{*} p<0.05 ;{ }^{* *} p<0.01$. 
Fall in

$\dot{\mathrm{V}}_{\mathrm{Imax}} \mathrm{mo}_{50}$

$\left(1 \mathrm{~s}^{-1}\right)$

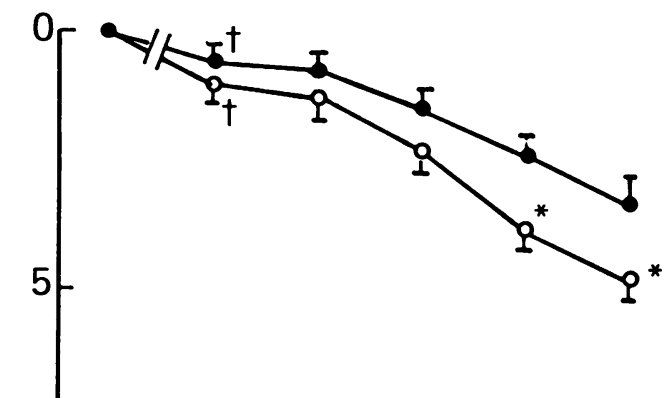

(a)

$10 \mathrm{~L}$

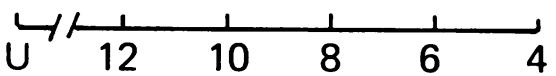

C ORIFICE SIZE (mm)

Fig 2 (continued)-see p464 for legend.

Fall in

$(\mathrm{PEF}$

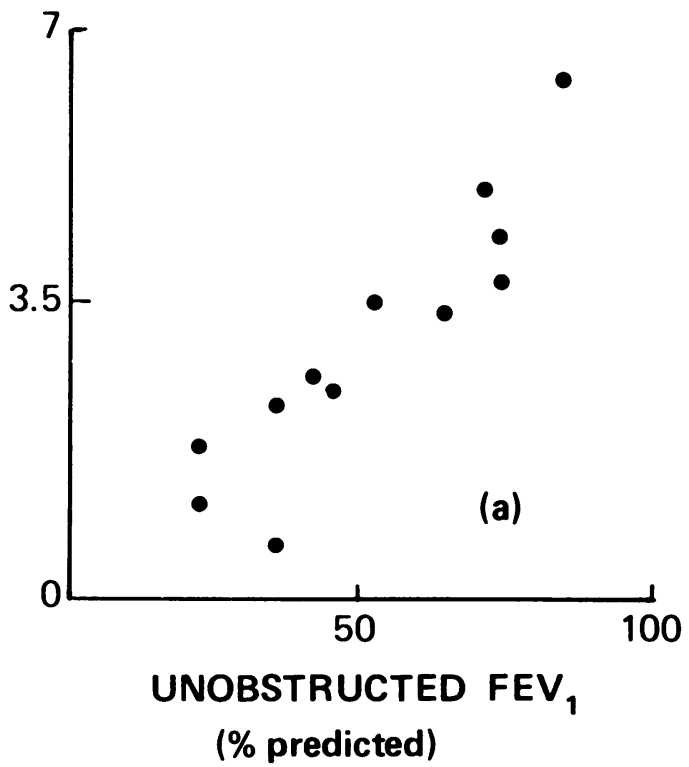

Fall in

$\dot{\mathrm{V}} \mathrm{max} \operatorname{mon}_{50}$

(\%)

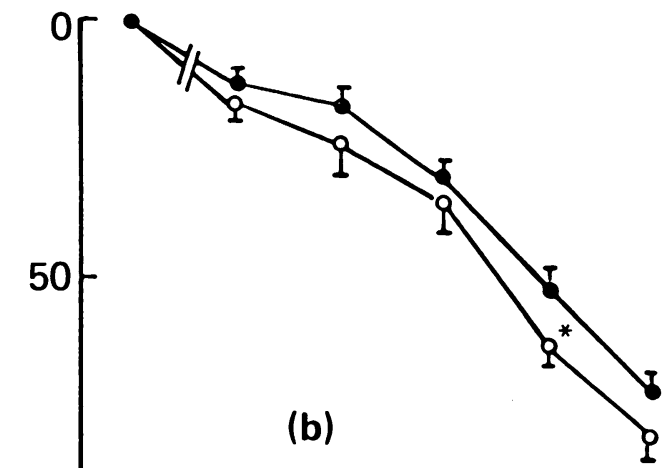

$100 \mathrm{~L}$

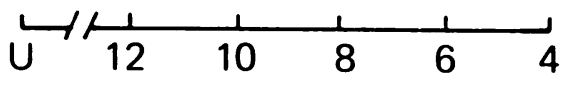

ORIFICE SIZE (mm)
Fall in

PEF

(\%)

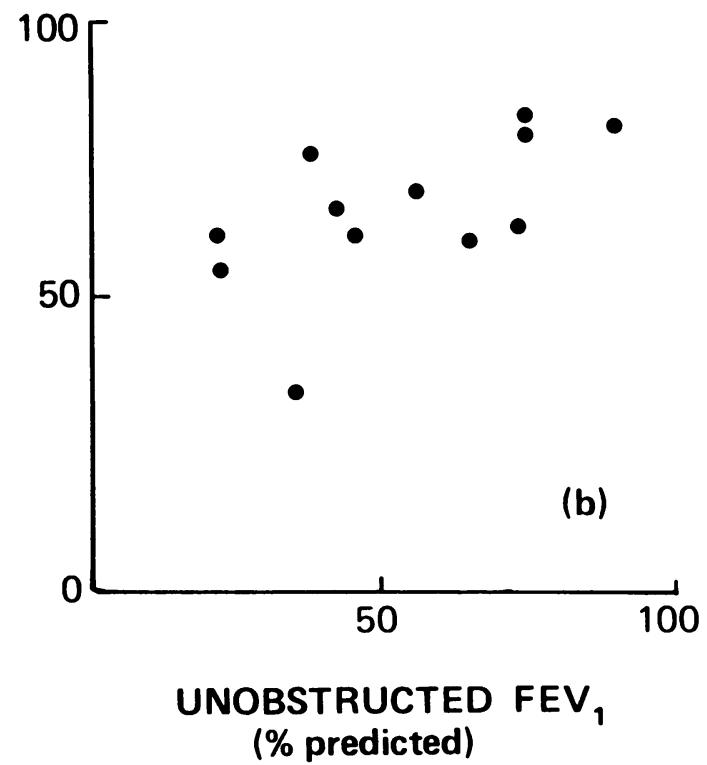

Fig 3 Relation between (a) the absolute and (b) the percentage reduction in peak expiratory flow (PEF) in the patients in the presence of a $4 \mathrm{~mm}$ simulated upper airways obstruction and the severity of chronic obstructive lung disease (expressed as percent predicted $F E V_{1}$ ). (a) $r=0.92 ; p<0.001$. (b) $r=0.54 ; p<0.05$. 


\section{$\%$}

change

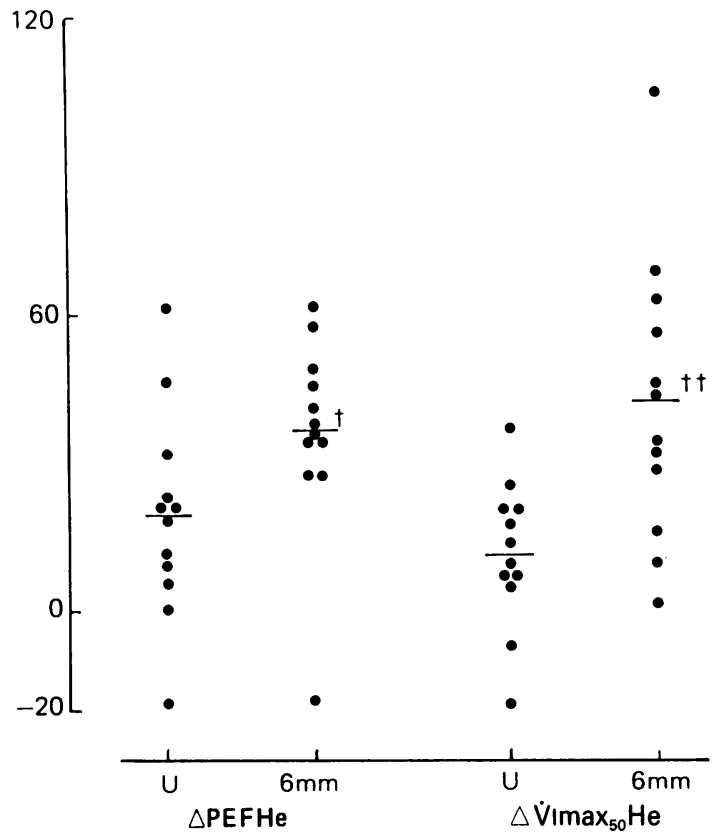

Fig 4 Values observed in the patients of $\triangle P E F$ and $\Delta V$ max $_{\text {so }}$ in the absence $(U)$ and in the presence of a $6 \mathrm{~mm}$ simulated upper airway obstruction. Significance of differences seen in the absence and in the presence of simulated upper airway obstruction: $\dagger p<0.05 ;+\dagger p<0.01$.

There was a close relation between $\mathrm{FEV}_{1} \%$ predicted and absolute fall in PEF, and even when the fall in PEF was expressed in percentage terms a significant correlation remained, smaller reductions in PEF being produced by the addition of the orifice in patients with more severe chronic obstructive lung disease.

Table 2 Mean (SD) percentage change in FEV and flows with subjects breathing heliox in the presence and absence of simulated upper airway obstruction (UAO) (6 mm orifice). All values were significantly different from zero in both subject groups except for $\Delta \dot{V}$ max $_{\mathrm{s0}}$ unobstructed in the patient group

\begin{tabular}{|c|c|c|c|c|}
\hline & \multicolumn{2}{|l|}{ Controls } & \multicolumn{2}{|l|}{ Patients } \\
\hline & No $U A O$ & $6 \mathrm{~mm} U A O$ & No UAO & $6 \mathrm{~mm} \mathrm{UAO}$ \\
\hline $\begin{array}{l}\Delta F E V_{1}(\%) \\
\Delta P E F(\%) \\
\Delta \operatorname{VEmax}_{s 0}(\%) \\
\Delta \operatorname{Vimax}_{50}(\%)\end{array}$ & $\begin{array}{r}4 \cdot 0(7 \cdot 3) \\
18 \cdot 3(12 \cdot 0) \\
21 \cdot 3(17 \cdot 1) \\
9 \cdot 7(25 \cdot 1)\end{array}$ & $\begin{array}{l}15.3(11 \cdot 5) \\
53.9(29.8)^{* *} \\
46 \cdot 2(28 \cdot 5)^{* *} \\
35.7(22.8)^{* *}\end{array}$ & $\begin{array}{l}14 \cdot 1(14 \cdot 1) \\
20 \cdot 1(21 \cdot 1) \\
22 \cdot 1(28 \cdot 9) \\
11 \cdot 8(15 \cdot 3)\end{array}$ & $\begin{array}{l}16 \cdot 0(9 \cdot 0) \\
36.5(20 \cdot 4)^{*} \\
18.0(28.4) \\
43 \cdot 2(28.3)^{* *}\end{array}$ \\
\hline
\end{tabular}

*Refers to differences within subjects in magnitude of heliox effect in the presence and absence of the orifice (that is, column $2 v$ column 1 and column $4 v$ column 3 respectively).

${ }^{*} \mathrm{p}<0.05 ; * * \mathrm{p}<0.01$.

For abbreviations see table 1
With milder degrees of simulated upper airway obstruction-for example, $8 \mathrm{~mm}$ - the correlations between PEF and the severity of chronic obstructive lung disease were less striking.

\section{EFFECT OF BREATHING HELIOX WITH AND WITHOUT SIMULATED UPPER AIRWAY OBSTRUCTION}

The changes in $\mathrm{FEV}_{1}$ and maximum flows in both subject groups breathing heliox in the presence and in the absence of a $6 \mathrm{~mm}$ orifice are summarised in table 2. With no additional obstruction heliox caused significant increases above values obtained during the breathing of air in FEV $1, P E F$, and $\dot{V}_{E m a x}$, both in the patients and in the normal controls. Increases in VImax $_{50}$ in the patients were not significant. In the presence of the orifice these increases were generally larger (except for $\Delta \dot{V}_{E^{\prime}} a_{50}$ in the patients). The increases in VImax $_{50}$ in the presence of the orifice were significant in both groups. Figure 4 illustrates (for the patient group only) the values of $\triangle \mathrm{PEF}$ and $\triangle \mathrm{VImax}_{50}$ both without obstruction and in the presence of a 6 $\mathrm{mm}$ orifice.

\section{Discussion}

Clinical experience suggests that the functional recognition of upper airway obstruction is difficult in patients who have diffuse intrathoracic airway narrowing. Gamsu et al ${ }^{11}$ compared flow-volume curves with bronchograms in 21 patients with upper airway obstruction and airway stenoses, and noted that all four patients with airway stenoses (identified bronchographically) but with no characteristic "plateau" of maximum expiratory flow on the flowvolume curve had "severe" chronic obstructive lung disease.

The present study has confirmed that the recognition of simulated upper airway obstruction is more difficult in patients with chronic obstructive lung disease than in the control subjects. The reductions in FEV 1 , PEF, and $\dot{V}_{1 m a x}$ produced by resistances added at the mouth were always less in the patients than in the control group.

The differences between the two groups could in part be related to the higher absolute starting values of the control group, but even when the reductions in $F V_{1}$ or maximum flow were expressed as percentages of the initial values significant differences between the two groups of subjects were still present (fig $2 b$ ). A lesser sensitivity of indices of maximum expiratory flow to upper airway obstruction in the patients would be expected as VEmax $_{50}$ is in general less effort dependent than it is in normal subjects, presumably owing to the more peripheral location of equal pressure points and flow limiting segments in the 
Table 3 Sensitivity and specificity (as percentages) of various indices for the identification of 6 mm simulated upper airway obstruction in patients with chronic obstructive lung disease and control subjects

\begin{tabular}{|c|c|c|c|c|}
\hline & \multicolumn{2}{|c|}{ Sensitivity } & \multicolumn{2}{|c|}{ Specificity } \\
\hline & Patients & Controls & Patients & Controls \\
\hline 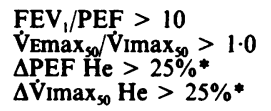 & $\begin{array}{l}58 \\
50 \\
92 \\
83\end{array}$ & $\begin{array}{r}100 \\
100 \\
75 \\
67\end{array}$ & $\begin{array}{r}100 \\
100 \\
75 \\
83\end{array}$ & $\begin{array}{r}100 \\
100 \\
75 \\
83\end{array}$ \\
\hline
\end{tabular}

* $\triangle \mathrm{PEF} \mathrm{He}$ and $\Delta \operatorname{Vimax}_{\mathrm{so}} \mathrm{He}$ represent the percentage changes in these indices after the breathing of heliox $(79 \%$ helium, $21 \%$ oxygen).

For abbreviations see table 1 .

patients. We have shown in addition a relation between the reduction in PEF with a $4 \mathrm{~mm}$ orifice and the FEV, with no obstruction (fig 3), showing that the more severe the diffuse airways obstruction the greater the difficulty likely to be encountered in recognising additional upper airway obstruction.

The indices most sensitive to the presence of upper airway obstruction in the patients and in the control group, in terms both of the largest orifice at which a significant reduction in flow was detectable and of the magnitude of reduction in flow, were PEF and V Imax $_{50}$ (fig 1). By contrast, VEmax ${ }_{50}$ and $F E V_{1}$ required more severe upper airway obstruction before they became significantly reduced. These results from normal subjects are in agreement with those of Miller and Hyatt. ${ }^{8}$ The trends were even more noteworthy in the patients. The greater sensitivity to upper airway obstruction of PEF and Vimax s0 $_{50}$ than of FEV 1 and $\dot{V}_{E m a x}{ }_{50}$ results from the greater dependence of the former measurements on effort than on dynamic compression of the intrathoracic airways.

As the smaller falls in FEV, PEF, and $\dot{V}_{1 m a x}$ in patients with chronic obstructive lung disease than in subjects with normal lungs may impair the recognition of upper airway obstruction, we have examined the sensitivity and specificity of two established indices for the recognition of upper airway obstruction in the control group and in the patients with chronic obstructive lung disease (table 3 ). In the presence of a $6 \mathrm{~mm}$ orifice the ratio $\operatorname{VEmax}_{50}$ : IImax $_{50}{ }^{2}$ exceeded 1.0 (suggesting upper airway obstruction) in all 12 control subjects but in only six of the patients. Similarly, with the same orifice the ratio $F E V_{1}: P^{\prime} F^{1}$ gave a value greater than or equal to $10 \mathrm{mll}^{-1} \mathrm{~min}$ (suggesting upper airway obstruction) in all 12 control subjects but in only seven patients. Thus, although these ratios are sensitive to simulated upper airway obstruction in subjects with otherwise normal lungs, their value in the recognition of upper airway obstruction is clearly reduced in subjects with generalised airflow limitation.
Comparisons of maximum expiratory flow during the breathing of air and heliox have been used mainly in studies aimed at the early detection of diffuse intrathoracic airway narrowing. The early promise of this technique as an epidemiological tool has not, however, been fulfilled, probably because the effects of breathing a low density gas on expiratory flow limitation are more complex than was originally realised. ${ }^{12}$ In the context of upper airway obstruction Barnett ${ }^{13}$ showed clearly that heliox had a particularly large effect on airflow when the central airway of dogs was artificially narrowed. Lavelle et $a l^{6}{ }^{6}$ however, found that the responses of maximum expiratory flow to heliox in a group of patients with upper airway obstruction were no greater than those of normal subjects with no obstruction. They also examined the effect of simulating upper airway obstruction in three patients with chronic obstructive lung disease and found that the responses to heliox were normal with the simulated obstruction but greater than the impaired responses seen when these patients were studied without artificial simulation of upper airway obstruction. They concluded that upper airway obstruction, if severe, may be identified in patients with chronic obstructive lung disease by the finding of a normal heliox response at high lung volumes. Our investigation extends the results of these studies by including a larger number of patients and measurements made also during forceful inspiration. The heliox studies were performed with a $6 \mathrm{~mm}$ orifice because this is about the level of obstruction at which upper airway obstruction becomes functionally important and also the level of simulated upper airway obstruction at which the heliox effect is reported as becoming large in normal subjects. ${ }^{6}$ With no additional obstruction, breathing heliox significantly increased $\mathrm{FEV}_{1}, \mathrm{PEF}$, and VEmax ${ }_{50}$ both in the patients and in the normal subjects. Vimax ${ }_{50}$ was significantly increased by heliox only in the normal subjects. The proportional increases in both groups of subjects were generally of similar magnitude. In the presence of a 6 $\mathrm{mm}$ orifice the values of $\triangle \mathrm{PEF}, \triangle \dot{\mathrm{V}} \mathrm{Emax}_{50}$, and

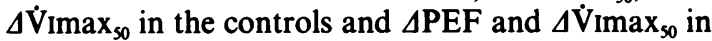
the patients were significantly larger than in the unobstructed state (table 2). These results suggest that in patients with generalised airflow limitation a large increase in PEF or VImax $_{s_{0}}$ while they are breathing heliox should raise the suspicion of upper airway obstruction. If values of $\triangle \mathrm{PEF}$ and $\Delta \dot{\mathrm{V}}_{\mathrm{Imax}}$ (with heliox) above $25 \%$ had arbitrarily been taken as indicators of underlying upper airway obstruction, then 11 and nine of the patients respectively would have been identified as having upper airway obstruction in the presence of a $6 \mathrm{~mm}$ orifice. This is a higher detection rate than would have been achieved by the traditional ratios FEV $_{1}:$ PEF or $\dot{V} \max _{50}:$ VIImax $_{50}$ 
(table 3). Because of the wide range of response seen with $\triangle \mathrm{PEF}$ and $\Delta \operatorname{VImax}_{s 0}$ (fig 4), however, their specificity is somewhat less.

In conclusion, we have confirmed the clinical impression that upper airway obstruction is more difficult to detect in the presence of generalised airways obstruction. The sensitivity and specificity of the traditional indices for the detection of upper airway obstruction in otherwise normal subjects have been confirmed, but these measurements are much less sensitive to upper airway obstruction in patients with chronic obstructive lung disease. Large increases in PEF or VImax ${ }_{50}$ during the breathing of heliox may aid the recognition of upper airway obstruction in patients with chronic obstructive lung disease, but the lack of specificity of such indices limits their clinical usefulness.

\section{References}

1 Empey DW. Assessment of upper airway obstruction. $\mathrm{Br}$ Med J 1972;iii:503-5.

2 Jordanoglou J, Pride NB. Comparison of maximum inspiratory and expiratory flow in health and in lung disease. Thorax 1968;23:38-45.

3 Miller RD, Hyatt RE. Evaluation of obstructing lesions of the trachea and larynx by flow-volume loops. $\mathrm{Am}$ Rev Respir Dis 1973;108:475-81.
4 Schilder DP, Roberts A, Fry DL. Effect of gas density and viscosity on the maximal expiratory flow-volume relationship. J Clin Invest 1963;42:1705-13.

5 Despas RJ, Leroux M, Macklem PT. Site of airway obstruction in asthma as determined by measuring maximal expiratory flow breathing air and a helium oxygen mixture. J Clin Invest 1973;51:3235-43.

6 Lavelle TF, Rotman HH, Weg JG. Isoflow-volume curves in the diagnosis of upper airway obstruction. Am Rev Respir Dis 1978;117:845-52.

7 Stanescu D, DesSutter P, van de Woestijne KP. Pressure corrected flow body plethysmograph. Am Rev Respir Dis 1972;105:304-5.

8 Miller RD, Hyatt RE. Obstructing lesions of the larynx and trachea: Clinical and physiological characteristics. Mayo Clin Proc 1969;44:145-61.

9 Peslin R, Bohadana A, Hanahart B, Jardin P. Comparison of various methods for reading maximal expiratory flow-volume curves. Am Rev Respir Dis 음 1979;119:271-8.

10 Quanjer PH, ed. Standardized lung function testing. Bull Eur Physiopathol Respir 1979;19(suppl 5):45-51.

11 Gamsu G, Borson DB, Webb WR, Cunningham JH. Structure and function in tracheal stenosis. Am Rev Respir Dis 1980;121:519-31.

12 Teculescu DB, Préfaut C. Why did density dependence of maximal expiratory flow not become a useful epidemiological tool? Clin Respir Physiol 1987;23: $639-48$.

13 Barnett TB. Effects of helium and oxygen mixtures on pulmonary mechanics during airway constriction. $J$ Appl Physiol 1967;22:707-13. 